\title{
Correlation between maximum isometric strength variables and specific performance of Brazilian military judokas
}

\author{
Michel Moraes Gonçalves1,5*, Claudio Joaquim Borba-Pinheiro ${ }^{3,4}$, Runer Augusto Marson'1, \\ Lucas Rodrigues Camposo ${ }^{2}$, Alam dos Reis Saraiva ${ }^{3,6}$, Jefferson da Silva Novaes ${ }^{5}$

\begin{abstract}
It was our objective to correlate specific performance in the Special Judo Fitness Test (SJFT) and the maximum isometric handgrip (HGSMax), scapular traction (STSMax) and lumbar traction (LTSMax) strength tests in military judo athletes. Twenty-two military athletes from the judo team of the Brazilian Navy Almirante Alexandrino Instruction Centre, with average age of $26.14 \pm 3.31$ years old, and average body mass of $83.23 \pm 14.14 \mathrm{~kg}$ participated in the study. Electronic dynamometry tests for HGSMax, STSMax and LTSMax were conducted. Then, after approximately 1 hour-interval, the SJFT protocol was applied. All variables were adjusted to the body mass of the athletes. Pearson correlation coefficient for statistical analysis was used. The results showed moderate negative correlation between the SJFT index and STSMax $(r=-0.550, p=0.008)$, strong negative correlations between the SJFT index and HGSMax $(r=-$ 0.706, $\mathrm{p}<0.001)$, SJFT index and LTSMax $(\mathrm{r}=-0.721 ; \mathrm{p}=0.001)$, besides the correlation between the sum of the three maximum isometric strength tests and the SJFT index $(r=-0.786, p<0.001)$. This study concludes that negative correlations occur between the SJFT index and maximum isometric handgrip, shoulder and lumbar traction strength and the sum of the three maximum isometric strength tests in military judokas.

Keywords: dynamometry muscle strength; judo; sports performance
\end{abstract}

\section{INTRODUCTION}

Judo is a combat sport featuring complex and multi-factorial characteristics for the athlete specific performance development, since it involves a variety of motor actions of different intensities, effort levels and fatigue (Amtmann \& Cotton, 2005; Olívio-Junior \& Drigo, 2015). Professional judo may cause damage to athletes, due to fast body fat loss, significant storage of blood lactate and increase in lesion risk (Azevedo et al., 2007; Franchini, Takito, \& Bertuzzi, 2005; Piucco \& Santos, 2010). Therefore, a high level of judo training requires specific planning, considering both the variables that can improve the athletes' performance and competition results and the protection of the body against those variables that negatively interfere in the training and competitions (Amtmann \& Cotton, 2005; Azevedo et al., 2007; Olívio-Junior \& Drigo, 2015; Piucco \& Santos, 2010; Saraiva et al., 2014).

The interest in high performance development for judo athletes is still recent in the scientific literature. However, specific training may potentially contribute to these athletes' success or failure (Olívio-Junior \& Drigo, 2015). In this way, studies trying to verify the associations among specific variables of judo athletes' performance might help to better understand the multi-factorial complexity of such combat sport, consequently helping to plan specific training.

Studies have demonstrated muscular strength in judo athletes to be a determinant variable for good results within specific performance in

Manuscript received at February 25 $5^{\text {th }} 2016$; Accepted at November $11^{\text {th }} 2016$

${ }^{1}$ Instituto de Pesquisa da Capacitação Física do Exército, IPCFEx, Rio de Janeiro, Brasil

${ }^{2}$ Escola de Educação Física do Exército, EsEFEx, Rio de Janeiro, Brasil

${ }^{3}$ Instituto Federal de Educação Ciência e Tecnologia do Pará, IFPA, Pará, Brasil

${ }^{4}$ Universidade do Estado do Pará, UEPA, campus de Tucuruí, Pará, Brasil

${ }^{5}$ Universidade Federal do Rio de Janeiro, UFRJ, Rio de Janeiro, Brasil

${ }^{6}$ Universidade de Trás-os-Montes e Alto Douro, UTAD, Vila Real, Portugal

* Corresponding author: Instituto de Pesquisa da Capacitação Física do Exército, Av. João Luiz Alves, S/nº, Urca CEP: 22291-090, Rio de Janeiro, Brasil.E-mail: michel_fitness@hotmail.com 
competitions as well as for body protection (Alves, Borba-pinheiro, Carvalho, ChulviMedrano, \& Dantas, 2012; Blais, Trilles, \& Lacouture, 2007). However, only few studies have been researching the correlation between the performance variables and specific performance (Bonitch-Góngora, BonitchDomínguez, Padial, \& Feriche, 2012; Franchini, Nunes, Moraes, \& Del Vecchio, 2007), thus justifying the present investigation, which brings forward the following issue: is there any statistical correlation between specific performance and the muscular strength variables in judo athletes?

The initial hypothesis stated that significant negative correlation would be found between the indexes of the special judo fitness test and the maximum isometric handgrip (HGSMax), scapular traction (STSMax) and lumbar traction (LTSMax) strength tests.

Thus, this study aims to verify possible statistical correlations between judo specific performance and maximum isometric muscle strength variables: handgrip, scapular and lumbar traction in judo military athletes.

\section{Participants}

\section{METHOD}

Participated in the present study 22 male athletes of the judo team of the Brazilian Navy Almirante Alexandrino Instruction Centre, with average age of $26.14 \pm 3.31$ years old, average body mass of $83.23 \pm 14.14 \mathrm{~kg}$ and average height of $1.77 \pm 0.06 \mathrm{~m}$.

To be included in the sample, the following criteria were observed: a) having experience with the Special Judo Fitness Test; b) training four to five times a week, and c) the judo specific training session needed to be at least 60 minutes long. The exclusion criteria were the following: a) current or previous injure in the dominant upper limb, b) use of heart rate altering drugs, c) total judo training time of less than one year and, according to Frabrini et al. (2010) d) no body mass reduction technique that might affect performance should be applied.

All volunteers were not elite athletes and they were aware of the procedures utilized in the research and of the importance of the objectives.
All subjects signed a free and informed consent form used in researches with human beings (Brasil, 2012). The research Project was approved by the Research and Ethics Committee of the State University of Pará/Brazil, under the protocol number CAAE: 0070.412.000-11.

Initially, all subjects informed their personal data through anamnesis, in order to assess the individual's aptitude to participate in the study.

\section{Instruments and Procedures}

Anthropometric Analysis

An estadiometer and a scale (model 31, Filizola", São Paulo, Brazil) were used, to measure height and body mass, which were assessed with precision of $0.5 \mathrm{~cm}$ and $0.1 \mathrm{~kg}$, respectively.

\section{Specific Performance Analysis}

For such analysis, the Special Judo Fitness Test (SJFT) was used, that is effectively presented in the literature by Sterkowicz and Franchini (1999), and normalized by Franchini, DelVecchio, and Sterkowicz (2006). The SJTF is a test which respects the judo specificity and simulates the fight metabolic request. The test is conducted at the athletes' training local, where they wear the training and competition outfit, the judogi, in order to measure the athletes' specific performance.

The SJFT protocol is described as follows: two judokas to be thrown (uke), of similar stature and body mass as the performer (tori), will be positioned at a 6-meter distance from one another and at a 3-meter distance from the tori. The test is divided into three periods, the first one of 15 seconds and the second and third ones of thirty seconds each, with a 10 seconds interval (static recovery) between each period. During these partial periods, the Tori must throw the two ukes as many times as possible, within the given time, using the ipon seoi nage technique. Such number of throws will be computed by the Sony ${ }^{\mathrm{m}}$ HDR-CX220 digital camera (Tokio-JA); the acute heart rate and the heart rate after a 1-minute recovery will be registered by the Polar ${ }^{\text {rw }}$ RS400 frequency meter (Kempele-FI). Then, the lowest indexes found will indicate the best test results. 
The index (SJFTI) is calculated through the following formula:

$$
\text { SJFTI }=\frac{\text { final HR }+ \text { HR } 1 \text { min after test end }}{\text { Total number of throws }}
$$

The structure below explains the SJFT execution framework:

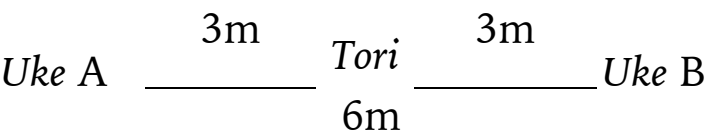

Table 1 shows the reference values for the SJFT classification.

Table 1

Special Judo Fitness Test Classification

\begin{tabular}{lcccc}
\hline Classification & Throws $\left(\mathrm{n}^{\circ}\right)$ & Final HR $(\mathrm{bpm})$ & 1 -min HR(bpm) & SJFT Index \\
\hline Excellent & $\geq 29$ & $\leq 173$ & $\leq 143$ & $\leq 11.73$ \\
Good & $27-28$ & $174-184$ & $144-161$ & $11.74-13.03$ \\
Average & 26 & $185-187$ & $162-165$ & $13.04-13.94$ \\
Poor & 25 & $188-195$ & $166-174$ & $13.95-14.84$ \\
Very poor & $\leq 24$ & $\geq 196$ & $\geq 175$ & $\geq 14.85$ \\
\hline
\end{tabular}

Note: HR - Heart Rate. Source: Franchini et al. (2009). Table 1: Index classification data resulting from the SJFT.

\section{Maximum Handgrip Strength Test (HGSMax)} Analysis

The Maximum Handgrip Strength (HGSMax) analysis identifies the individual's handgrip strength. It is indicated by the American Society of Hand Therapists (ASHT) and it is widely used to assess such type of strength in judokas (Lima, Kubota, Monteiro, Baldan, \& Pompeu, 2014).

The athletes were comfortably seated, with their dominant upper limb to the side of their body with slight adduction, their elbow flexed at $90^{\circ}$, forearm in neutral position and wrist extension able to vary between $0^{\circ}$ and $30^{\circ}$. The HGSMax was measured by a JAMAR " strength dynamometer, which is a hydraulic instrument widely used to assess handgrip strength. Three different trials were performed, since the study conducted by Mathiovetz, Weber, Yolland, and Kashman (1984) showed greater test-retest reliability when using three trials (0.883), compared to one (0.788) or two trials (0.862).

The test was conducted using a familiarization session, consisting of sub-maximal HGSMax contractions. Then, three 10 seconds series were performed, where the dominant hand contraction time lasted for the last 6 seconds of each series, with a 90 seconds interval between them. The best dominant upper limb result out of the three trials was considered.
Maximum Scapular Traction Strength Test (STSMax) Analysis

Immediately after the last handgrip test execution, the athlete was directed to the Maximum Scapular Traction Strength Test (STSMax). In order to assess the STSMax, a standard procedure was applied, described by Soares, Júnior, Franchini, Domenech, and Júnior (2012), where the individual needs to be standing with shoulder abduction, elbow flexion, forearm in neutral position, slight wrist extension, thumb extension and abduction and only the rest of the fingers touching the handle. The individual is instructed to apply a traction force to the sides (20 cm distance between hands). The STSMax was assessed using an electronic dynamometer, model TRF200" EMG System (Brazil) with a flexible shielded 2-meter cable, and with a data acquisition system allowing for reading up to 200 N. A familiarization session was conducted, consisting of sub-maximal STSMax contractions. Then, three 10 seconds series were performed, where the contraction time lasted for the last 6 seconds of each series, with a 90 seconds interval between them. The best result out of the three trials was considered.

Maximum Lumbar Traction Strength Test (LTSMax) Analysis

Finally, after the STSMax test, the athlete was guided to the Maximum Lumbar Traction Strength Test (LTSMax). In order to assess the 
LTSMax, a standard procedure described by Soares et al. (2012) was applied, where a barefoot individual was positioned on a platform containing a charge-coupled cell. The subject was instructed to keep the spine erect, and the arms extended in front of the thighs, in order to correctly execute the traction. Then, the individual needed to flex the trunk forward, slightly flex the knees and hold the handle, applying the maximum traction strength with the hands on the handle, perpendicularly to the platform, without letting the handle or the hands touch any other part of the body. Three repetitions of 10 seconds were performed, where the contraction time for measuring the LTSMax lasted for the last 6 seconds of each repetition, with a 90 seconds interval between them. As with the other tests, the best result out of the three trials was considered.

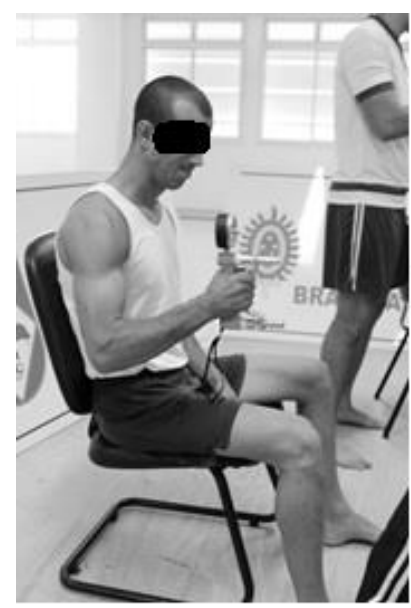

A

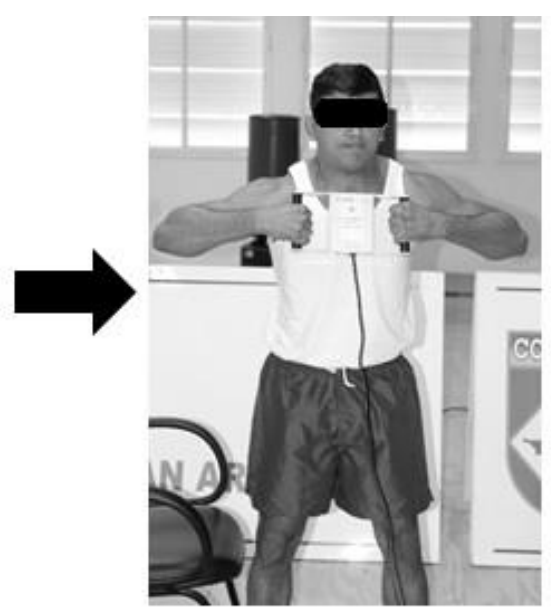

$\mathrm{B}$

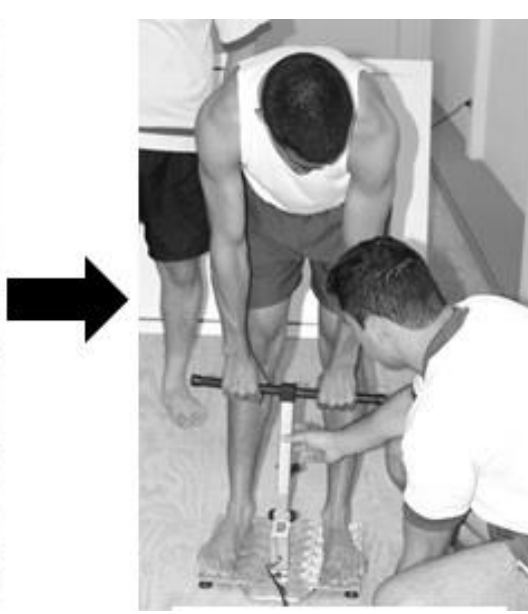

C

Figure 1. Strength tests performed in this study. A) identifies the handgrip test; B) identifies the scapular traction test; and C) points out the lumbar traction test.

Sum of the Three Isometric Strength Tests ( 53 tests)

After conducting all analyses, the sum of the results from the HGSMax, STSMax, and LTSMax was conducted, in order to correlate the total isometric strength peak of the three tests with the SJFT.

It is worth highlighting that all analysed variables (HGSMax, STSMax, and LTSMax, $\Sigma 3$ tests and SJFT index) have been adjusted to the body mass of the studied athletes, calculated through the following equation:

$$
\text { Adjusted Variable }=\frac{\text { Analysed Variable }}{\text { Mass }}
$$

\section{Statistical Analysis}

Statistical analysis was conducted using the SPSS software for Windows 20.0, setting the significance level at $\mathrm{p}<0.05$. A normality analysis was applied, using the Shapiro Wilk test, where the data fell within a normal distribution curve and, due to this, the Pearson correlation coefficient was used to verify possible correlations among the studied variables.

A descriptive analysis of the data characterizing the sample was conducted.

\section{RESULTS}

Table 2 shows the descriptive data, classifying them into weight categories of the studied judokas and variable values: age, body mass, height, HGSMax, STSMax, LTSMax, $\Sigma 3$ tests and SJFT index (SJFTI).

Figure 2 shows the results for the statistical correlation between the SJFT index and the strength tests: HGSMax, STSMax, LTSMax, and $\Sigma 3$ tests adjusted to the athletes' body mass. The results show strong negative correlation between the SJFT and the LTSMax and HGSMax; moderate negative correlation was also found between the SJFT and STSMax. In addition, the sum of the three maximum strength tests showed strong negative correlation with the SJFT. 
Table 2

Descriptive Data of the Studied Sample

\begin{tabular}{|c|c|c|c|c|c|c|c|c|c|c|}
\hline \multirow{6}{*}{ 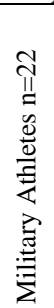 } & $\begin{array}{l}\text { Weight } \\
\text { Category } \\
(\mathrm{kg})\end{array}$ & $\mathrm{n}$ & Age (years) & $\begin{array}{l}\text { Body mass } \\
(\mathrm{kg})\end{array}$ & Height (m) & $\underset{(\text { Kgf) }}{\text { HGSMax }}$ & $\begin{array}{l}\text { LTSMax } \\
\text { (Kgf) }\end{array}$ & $\begin{array}{l}\text { STSMax } \\
(\mathrm{Kgf})\end{array}$ & $\Sigma 3$ tests & SJFT (score) \\
\hline & -66 & 4 & $24 \pm 3.5$ & $63.5 \pm 2.08$ & $1.73 \pm 0.07$ & $48.5 \pm 7.8$ & $124.2 \pm 22.1$ & $26.5 \pm 8.2$ & $200.4 \pm 18.7$ & $14.2 \pm 0.95$ \\
\hline & -73 & 3 & $24.6 \pm 4.6$ & $72.3 \pm 0.57$ & $1.76 \pm 0.07$ & $50.6 \pm 4.04$ & $146 \pm 11.8$ & $27.6 \pm 2.5$ & $225.1 \pm 1.4$ & $14.6 \pm 0.57$ \\
\hline & -81 & 4 & $28.5 \pm 2.1$ & $79.5 \pm 3.1$ & $1.75 \pm 0.05$ & $55.7 \pm 8.1$ & $122 \pm 16.8$ & $29.5 \pm 8.4$ & $208.2 \pm 33.3$ & $14.0 \pm 1.41$ \\
\hline & -90 & 5 & $26 \pm 3.4$ & $87.4 \pm 2.9$ & $1.79 \pm 0.04$ & $51.6 \pm 3.8$ & $129 \pm 26.5$ & $26.8 \pm 6.1$ & $208.2 \pm 43.5$ & $15.6 \pm 1.51$ \\
\hline & -100 & 3 & $25.6 \pm 3.1$ & $94.6 \pm 2.08$ & $1.75 \pm 0.03$ & $45.6 \pm 6.8$ & $141 \pm 12.1$ & $30.0 \pm 6.5$ & $217.7 \pm 19.1$ & $16.6 \pm 0.57$ \\
\hline & +100 & 3 & $25 \pm 4$ & $106.6 \pm 4.1$ & $1.84 \pm 0.01$ & $47.0 \pm 7$ & $123.3 \pm 13.1$ & $24.0 \pm 2.6$ & $195.8 \pm 6,0$ & $16.3 \pm 1.85$ \\
\hline
\end{tabular}

HGSMax = Maximum Handgrip Strength; LTSMax = Maximum Lumbar Traction Strength; STSMax = Maximum Scapular Traction Strength; $\Sigma 3$ tests $=$ sum of the three maximum isometric strength tests; SJFT $=$ Special Judo Fitness Test

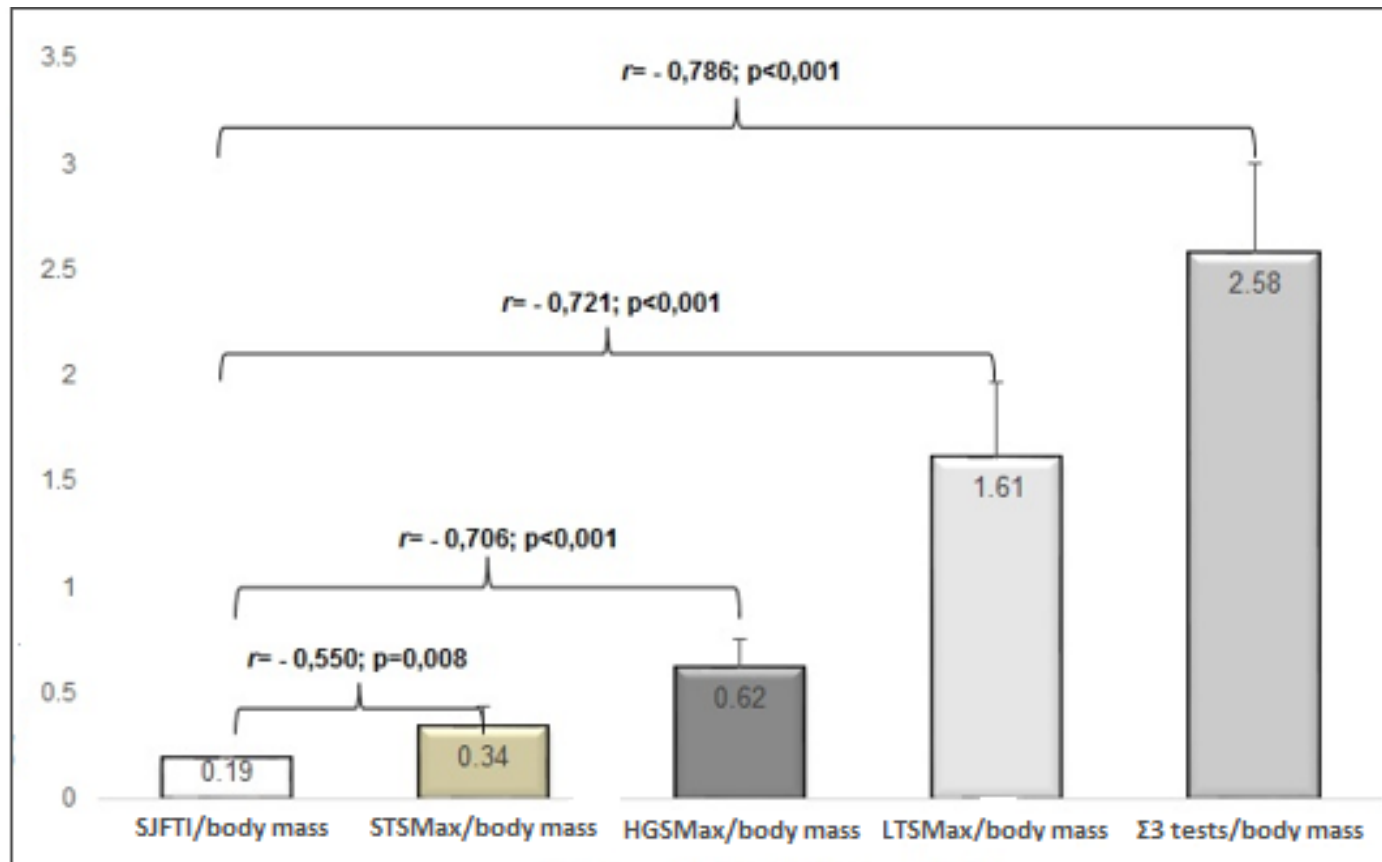

Figure 2. Results of correlation between the SJFT and Maximum Handgrip Strength test (HGSMax), Maximum Lumbar Traction Strength test (LTSMax), Maximum Scapular Traction Strength Test (STSMax) and Sum of the Three Isometric Strength Tests ( $\Sigma 3$ tests), all adjusted to body mass.

\section{DISCUSSION}

The present study aimed to find possible statistical correlations between the judo specific performance and maximum isometric muscle strength variables (handgrip, scapular and lumbar traction) of judo military athletes. The main results indicated negative correlations between the maximum strength tests and the SJFT index.

The importance of muscle strength for highperformance judokas was already analysed in a few studies. Franchini, Miarka, Matheus, and Del Vecchio (2011) showed high level fighters to feature better results in dynamic strength endurance tests in bar pull-ups grabbing the Judo-Gi (12 \pm 5 repetitions), when compared to regional level judokas (9 \pm 4 repetitions). Another study showed high-performance judokas to feature significant arm strength improvement $(\Delta \%=48.2 \% ; \mathrm{p}=0.0006)$ after a training period (Alves et al., 2012). Lima, Kubota, Monteiro, Baldan, and Pompeu (2014) have also demonstrated judo black belt athletes to feature better handgrip strength $(\mathrm{p}<0.05)$, compared to judo white belt ones. In another study by Sánchez, Domínguez, Turpin, Tormo, and Llorca (2011), bilateral handgrip strength was assessed in 102 judokas, aged between 15 and 19 years, members of the 2008 Gales/Spain Junior League, and significant difference was found among the heavy weight male categories. Sterkowicz et al. (2011) showed the knee extensor muscle relative 
strength in young Polish judokas to be greater than in the sedentary group; the same also occurred for the trunk flexion-extension strength. In addition, Soares et al. (2012) found correlation among the isometric handgrip, scapular and lumbar traction strength variables, which were analysed in the present study.

The results from the aforementioned studies show the need for handgrip, arm and trunk strength use both for high-performance judokas and for junior athletes competing at regional level, thus corroborating the results from this study, since the need for developing such associated variables refers to athletes of all different classes and categories, as well as to military athletes.

The complexity of the judo combat underlines the necessity for muscle strength of the utilized muscle groups during competition, especially those used in offensive and defensive actions, such as the paravertebral muscles of the lumbar region, widely used in these actions to keep the static-dynamic balance (Olívio-Júnior \& Drigo, 2015). Consequently, the specific strength variables and the SJFT index report may be a fundamental factor for the final performance in competitions and/or lesion prevention (Drid et al., 2011; O'Donovan, Cheung, Catley, McGregor, \& Strutton, 2006). Nevertheless, it is necessary to remember that the dynamics complexity of the judo combats, particularly characterized by the variability of different intensity motor actions, needs specific planning that considers the many factors involved (Olívio-Júnior \& Drigo, 2015; Sterkowicz, Lech, \& Almansba, 2010; Verkoshansky, 1990). Thus, the strength training will need to be adjusted to technical training. Considering this, Blais and Trilles (2006) studied the execution time of two projection techniques (Soto Gari and Morote Seoi Nague) during a period of strength training with a specific machine, combined with technical training, and found significant results for better execution time of such techniques $(\mathrm{p}<0.05)$.

Lech, Tyka, Palka, \& Krawczyk (2010) suggested paying greater attention to training periodization for high-performance judokas, since this allows for better motor performance during combat. Another study analysed 14 judoka finalists at the 2005 European Championship, ratifying that specific actions during combat require high levels of functional strength for performance success in competitions (Boguszewski \& Boguszewska, 2006). Such need for high performance during combat reinforces the results found in the present study, where greater maximum isometric handgrip, scapular and lumbar traction strength, as well as the sum of the three, is inversely related to SJFT execution time for specific performance.

The importance of high-performance judokas' global training has become a topic of interest for researchers, as to improve physical performance, lesion protection, technical ability, and psychological preparation (Olívio-Júnior \& Drigo, 2015; Sterkowicz et al., 2010). In order to further investigate such topic, Blais, Trilles, \& Lacouture (2007) validated a machine for strength specific training using the technical movement of judo projections. The study found statistical difference for the pulling strengths (collar and sleeve) favourable to the movement executed with the machine, compared to the movement traditionally executed against the opponent. This may be explained due to the fact of the partner opposing lower resistance during the throwing technique, compared to the specific resistance machine for the judo throwing technique.

The present study indicated maximum handgrip, scapular and lumbar traction muscle strength, as well as the sum of all three, to show correlation with specific performance through the SJFT. This points out to the need of school level, regional level, military and high-performance judokas to have a period of specific training, including technical / physical / functional / training associated to a specific strength. Such information is important, since, according to Deval, García, and Monteiro (2009), judokas are characterized by the fact of mainly using the tewaza techniques in competitions, mostly applying hand/arm techniques, such as the SeoiNage; these techniques require greater arm, shoulder and lumbar muscle strength, thus supporting the correlations found in this study about specific performance and maximum strength of specific body regions. 
A study verified the association between handgrip strength and blood lactate concentration in national level male judokas during a competition, and significant inverse relation $(\mathrm{p}<0.05)$ was found between such variable, especially for the non-dominant hand, where increase in the lactate concentration and decrease in the handgrip strength were observed after the first, third, and fourth fight (BonitchGóngora et al., 2012). Another study analysed the correlation among judoka variables, finding association $(\mathrm{p}<0.05)$ between the $\mathrm{VO}_{2 \max }$ (maximal oxygen uptake) and the number of throws in the SJFT, besides the association between the fat percentage and the number of throws in the SJFT, thus concluding that those athletes with greater aerobic power featured better performance at high intensity, and that higher body fat percentage is negatively related to performance in activities with body mass movement (Franchini et al., 2007).

Among the researchers of the judo combat complexity, Olívio-Júnior and Drigo (2015) showed a basis for such complexity, under the name of judo combat functional units, in which the fight characteristics and necessities are considered to be as follows: 1-moment, 2-units, 3-sub-units e 4-micro-units. The moments have been characterized together with their units as follows: a) pre-contact, aimed at approximation and actual contact; b) standing control, aimed at contact, opportunity creation, unbalance, application and projection; c) transitioning control, aimed at unbalance, application, projection and transition from standing to floor combat, and d) floor control, aimed at the transition and actual combat on the ground. Each unit features sub-units, where all contribute to the effectiveness of offensive and defensive actions, either standing or on the floor; therefore, the micro-units are movements towards different directions, advantage and disadvantage positions, among others, and aim at the most refined movements within the technical training for actual combat approximation. The results of the present study agree with the judo combat complexity presented by Olívio-Júnior and Drigo (2015), since the association between the maximum isometric strength variables and specific performance are observed within the judo combat functional units suggested by these authors.

Such issues related to judo combat have also been studied by other authors (Carballeira \& Iglesias, 2007; Franchini, 2001; Sterkowicz, Garcià, \& Lerma, 2007; Sterkowicz et al., 2011), and, due to this, judoka training periodization needs to consider the complex interaction among the physical, technical, functional and emotional variables for the effective conditioning of these athletes.

Nonetheless, future studies with judo elite athletes need to be conducted, using these and other variable interactions, to better understand the judo combat complexity and the need for greater specificity in training planning.

\section{CONCLUSIONS}

In conclusion, this study showed strong negative correlations to occur between the SJFT index, the maximum isometric handgrip, shoulder traction and lumbar traction strengths, and the sum of all three isometric test results, adjusted to the body mass of the military judokas. Considering this, it is possible to say that the athletes with the best performance in the SJFT, that is, lowest test index, were those athletes who also obtained better levels of maximum isometric strength.

\section{Acknowledgments:}

We thank the command of the Physical Capacitating Center of the Brazilian Army and to the Almirante Alexandrino Instruction Center of the Brazilian Navy.

Conflict of interest:

Nothing to declare

Funding:

Nothing to declare

\section{REFERENCES}

Alves, J., Borba-pinheiro, C. J., Carvalho, M. C. G., Chulvi-Medrano, I., \& Dantas, M.E.H. (2012). Fuerza muscular y flexibilidad de judokas masculinos de alto rendimiento que participaron en la liga española durante 2011. Motricidad Humana, 13, 28-35. 
Amtmann, J., \& Cotton, A. (2005). Strength and Conditioning for Judo. Strength and Conditioning Journal, 27(2), 26-31.

Azevedo, P. H. S. M., Drigo, A. J., Carvalho, M. C. G. A., Oliveira, J. C., Nunes, J. E. D., Baldissera, V., \& Perez, S. E. A. (2007). Determination of judo endurance performance using the Uchi - Komi technique and an adapted lactate minimum test. Journal of Sports Science and Medicine, 6(CSSI-2), $10-14$.

Blais, L., \& Trilles, F. (2006). The progress achieved by judokas after strength training with a judospecific machine. Journal of Sports Science and Medicine, 5(CSSI), 132-135.

Blais, L., Trilles, F., \& Lacouture, P. (2007). Validation of a specific machine to the strength training of judokas. Journal of Strength and Conditioning Research, 21 (2), 409-12.

Brasil. (2012) Resolução 466/12 do Conselho Nacional de Saúde do Brasil que trata de pesquisas envolvendo seres humanos, dezembro, 2012. Retrieved

from http://conselho.saude.gov.br/resolucoes/2012/ Reso466.pdf/

Boguszewski, D., \& Boguszewska, K. (2006). Dynamics of judo contests performed by finalists of European Championships (Rotterdam 2005). Archives of Budo, 2, 40-44.

Bonitch-Góngora, J. G., Bonitch-Domínguez, J. G., Padial, P., \& Feriche, B. (2012). The effect of lactate concentration on the handgrip strength during judo bouts. Journal of Strength and Conditioning Research, 26(7), 1863-1871.

Carballeira, E., \& Iglesias, E. (2007). Efectos agudos del enfrentamiento en judo: análisis multiparamétrico. European Journal Human of Movement, 19, 117-144.

Deval, V. C., García, J. M. G., \& Monteiro, F. L. (2009). Análisis de las acciones técnicas de los judokas cadetes participantes en el campeonato de España. Revista Internacional de Ciencias del Deporte, 15(5), 64-80. Retrieved from http://www.cafyd.com/ REVISTA/01505.pdf/

Drid, P., Ostojic, S. M., Vujkov, S., Purkovic, S., Trivic, T., and Stojanovic, M. (2011). Physiological adaptations of a specific muscle-imbalance reduction training programme in the elite female judokas. Archives of Budo, 7(2), 61-64.

Fabrini, S. P., Brito, C. J., Mendes, E. L., Sabarense, C. M., Marins, J. C. B., \& Franchini, E. (2010). Práticas de redução de massa corporal em judocas nos períodos pré-competitivos. Revista Brasileira de Educação Física e Esporte, 24(2), 165-177.

Franchini, E. (2001). Judô Desempenho Competitivo. ( $1^{\text {st }}$ ed.). São Paulo, Brasil: Manole.

Franchini, E., Takito, M. Y., and Bertuzzi, R. C. M. (2005). Morphological, physiological \& technical variables in high-level college judoists. Archives of Budo, 1, 1-7.

Franchini, E., DelVecchio, F. B., \& Sterkowicz S. (2006). Classificatory norms to the Special Judo
Fitness Test. $1^{\circ}$ Word Scientific Congress of Combat. Sports and Matial Artsin Rzeszow, 9, 64.

Franchini, E., Miarka, B., Matheus, L., \& Del Vecchio, F.B. (2011). Endurance in judogi grip strength tests: Comparison between elite and non-elite judo players. Archives of Budo, 7(1), 1-4.

Franchini, E., Nunes, A. V., Moraes, J. M., \& Del Vecchio F. B. (2007). Physical fitness and anthropometrical profile of the Brazilian male judo team. Journal of Physiological Anthropology, 26(2), 59-67.

Lima, M. C., Kubota, L. M., Monteiro, C. B. M., Baldan, C. S., \& Pompeu, J. E. (2014). Força de preensão manual em atletas de judô. Revista Brasileira de Medicina do Esporte, 20(3), 210-213. doi: 10.1590/1517-86922014200301525.

Lech, G., Tyka, A., Palka, T., \& Krawczyk, R. (2010). Effect of physical endurance on fighting and the level of sports performance in junior judokas. Archives of Budo, 6(1), 1-6.

Mathiowetz, V., Weber, K., Yolland, G., \& Kashman, N. (1984). Reliability and validity of grip and pinch strength evaluations. Journal of Hand Surgery (America Volume), 9(2), 222-226.

O’Donovan, O., Cheung, J., Catley, M., McGregor, A. H., \& Strutton, A. H. (2006). An investigation of leg and trunk strength and reaction times of hardstyle martial arts practitioners. Journal of Sports Science and Medicine, 5(CSSI), 5-12.

Olívio-Junior, J. A., \& Drigo, A. J. (2015). Pedagogia complexa do Judô: um manual para treinadores de equipes de base. ( $1^{\text {st }}$ ed.). Leme, Brasil: Mundo Jurídico.

Piucco, T., \& Santos, S.G. (2010). Valores de impacto no corpo do judoca ao ser projetado pela técnica Ippon-Seoi-Nage. Motricidade; 6(1), 71-83. doi: 10.6063/motricidade.6(1), 71-83.

Sánchez, Á. G., Domínguez, A. S., Turpin, J.A. P., Tormo, J. M. C., \& Llorca, C. S. (2011). Importance of hand-grip strength as an indicator for predicting the results of competitions of young judokas. Archives of Budo, 7(3), 167-172.

Saraiva, A. R., Reis, V. M., Costa, P. B., Bentes, C. M., Silva, G. V. C., \& Novaes, J. S. (2014). Chronic Effects of Different Resistance Training Exercise Orders on Flexibility in Elite Judo Athletes. Journal of Human Kinetics, 40(1), 129-137. doi: 10.2478/hukin-2014-0015.

Soares, A. V., Júnior, J. M. C., Franchini, E., Domenech, S. C., \& Júnior, N. G. B. (2012). Correlação entre os testes de dinamometria de preensão manual, escapular e lombar. Acta Brasileira do Movimento Humano, 2(1), 65-72.

Sterkowicz, S., \& Franchini, E. (1999). Analysis of a specific judo test. Revista Kinesis, 21, 91-108.

Sterkowicz, S., Garcià, J. M. G., \& Lerma, F. S. (2007). The importance of judo trainers' professional activities. Archives of Budo, 3, 57-61.

Sterkowicz, S., Lech, G., Chwala, W., Ambrozy, T., Jaworski, J., \& Klys, A. (2011). Muscle strength in young judo contestants vs. untrained subjects. Archives of Budo, 7(3), 179-184. 
76 | MM Gonçalves, CJ Borba-Pinheiro, RA Marson, LR Camposo, AR Saraiva, JS Novaes

Sterkowicz, S., Lech, G., \& Almansba, R. (2010). The course of fight and the level of sports achievements in judo. Achives of Budo, 6(1), 1-6.
Verkoshansky, Y. V. (1990). Entrenamiento deportivo: planificación e programación. ( $1^{\text {st }}$ ed.). Barcelona, Espanha: Martinez Roca.

(c) (i) (9) All content of Journal Motricidade is licensed under Creative Commons, except when otherwise specified and in content retrieved from other bibliographic sources. 